This accepted author manuscript is copyrighted and published by Elsevier. It is posted here by agreement between Elsevier and MTA. The definitive version of the text was subsequently published in [Psychoneuroendocrinology, Vol. 47., September 2014, DOI 10.1016/j.psyneuen.2014.05.010]. Available under license CC-BY-NC-ND. 


\title{
The effects of vasopressin deficiency on aggression and impulsiveness in male and female rats
}

\author{
5 Q1 Anna Fodor a,b, Beata Barsvari ${ }_{\wedge}^{a}$, Mano Aliczki ${ }_{\wedge}^{a, *}$, Zoltan Balogh ${ }_{\wedge}$ \\ , Dora Zelena, ${ }_{\wedge}^{a}$, Steven R. Goldberg ${ }^{\mathrm{c}}$, , Jozsef Haller ${ }_{\wedge}^{\mathrm{a}}$ \\ a Department of Behavioural Neurobiology, Institute of Experimental Medicine, Hungarian Academy of \\ Science, Budapest, Hungary \\ b Janos Szentagothai School of Neurosciences, Semmelweis University, Budapest, Hungary \\ c Department of Health and Human Services, Preclinical Pharmacology Section, Intramural Research \\ Program, National Institute on Drug Abuse, National Institutes of Health, Biomedical Research Center, \\ Baltimore, USA
}

Received 5 February 2014; received in revised form 19 May 2014; accepted 19 May 2014

\author{
KEYWORDS \\ Aggression; \\ Brattleboro rat; \\ Impulsiveness; \\ Maternal aggression; \\ Resident-intruder \\ test; \\ Vasopressin
}

\begin{abstract}
Summary The role of vasopressin in aggression received much attention in recent years. However, vasopressin has complex roles on social behavior, which are affected by social experience, motivation and hormonal background, suggesting that its effects depend on the condition of subjects. This hypothesis was tested here by studying the impact of vasopressin deficiency on aggressiveness in reproductively naive and reproductively experienced males, as well as in lactating females, with special reference to the patterns and contexts of attack behavior. We also studied effects on impulsiveness, a behavioral feature strongly related to aggression. Vasopressin deficiency did not affect aggressiveness in reproductively experienced males, decreased the share of violent attacks in reproductively inexperienced males without affecting total attack counts, and suppressed maternal aggression in both early and late phases of lactation; violent forms of attack were decreased in the latter but not the former phase. Changes in aggression appeared unrelated to general changes in maternal behaviors. Impulsivity in the delay discounting task was markedly decreased by vasopressin deficiency in lactating females but not males. Taken together, our findings confirm that vasopressin has an impact on aggressiveness, but show that this impact depends on the condition of subjects, and suggest that the effects of vasopressin on maternal aggression develop in conjunction with impulsivity. Interestingly, overall effects on aggression and specific effects on violent attacks dissociated in both males and
\end{abstract}

* Corresponding author at- Repartment of Behavioral Neurobiology, Institute of Experimental Medicine, Hungarian Academy of Sciences, P.O. Box 67, 1450 Budape 5 ungary. Tel.: +36 12109408; fax: +36 12109951.

E-mail address: aliczk.rmaho@koki.mta.hu (M. Aliczki). 
females, which hints to the possibility that vasopressin has distinct roles in the development of escalated forms of aggression.

(c) 2014 Published by Elsevier Ltd.

\section{Introduction}

The first evidence on the role of vasopressin in aggressive behavior comes from the study by Ferris and Potegal (Ferris and Potegal, 1988; Ferris et al., 1997), who showed that vasopressin receptor blockade in the anterior hypothalamus (a brain region crucially involved in aggression control, see Haller, 2013 for a review) specifically reduces aggression in hamsters. Subsequent studies confirmed these findings. Aggressive interactions increase vasopressin release in particular brain regions (Compaan et al., 1993; Beiderbeck et al., 2007; Gobrogge et al., 2009; Neumann et al., 2010; Veenema et al., 2010; Bosch, 2013; Cordero et al., 2013), while vasopressin released by aggressive encounters positively affected the expression of aggressive behaviors in a variety of paradigms and species (maternal aggression (Nephew et al., 2010; Bosch and Neumann, 2012); residentintruder test (Cervantes and Delville, 2007; Carrillo et al., 2011); predator defense (Griebel et al., 2002); play-fighting (Cheng and Delville, 2009)). The inhibition of vasopressin $\mathrm{V} 1 \mathrm{a}$ and $\mathrm{V} 1 \mathrm{~b}$ receptors have similar effects on both maternal and male aggression (Ferris and Potegal, 1988; Caldwell and Young, 2009; Bosch and Neumann, 2012; Stevenson and Caldwell, 2012), while the level of V1a receptor expression in particular brain areas correlates positively with aggressiveness (Gobrogge et al., 2009; Caughey et al., 2011). It occurs that vasopressin affects human aggression in a similar manner (Coccaro et al., 1998; Zai et al., 2012). Taken together, these findings suggest that vasopressin is involved in the positive modulation of aggressiveness.

However, the link between aggressiveness and vasopressin neurotransmission is not as clear-cut as the above review of findings suggests. Firstly, the effects of vasopressin are strongly brain area dependent; e.g. vasopressin neurotransmission in the lateral septum and bed nucleus of stria terminalis promote and inhibit, respectively, aggressive behavior (Veenema et al., 2010; Kelly and Goodson, 2013). Secondly, and more importantly for the present study, the effects of vasopressin release depend on the characteristics of, and type of aggressive behavior shown by subjects. E.g., the dramatic increase in adult aggressiveness induced in hamsters by repeated defeats during adolescence was associated with reduced vasopressin content in the anterior hypothalamus, a key region of aggression control (Delville et al., 1998), despite the fact that vasopressin release in the very same brain area promotes aggressiveness in this species (Ferris and Potegal, 1988). Findings on vasopressin neurotransmission in the lateral septum were similarly model-dependent. Rats selected for low anxiety show high levels of aggression, attack vulnerable body parts of their opponents (head, throat and belly), and attack females and narcotized opponents, demonstrating strongly disturbed aggressive behavior (Neumann et al.,
2010; Beiderbeck et al., 2012). In these rats, vasopressin release in the lateral septum was decreased, and the local administration of vasopressin did not affect aggressiveness (Beiderbeck et al., 2007), despite the fact that vasopressin release in the same brain area strongly promoted aggression in rats not selected for anxiety (Veenema et al., 2010). In a recent study, plasma levels of vasopressin showed a positive correlation with aggressiveness in female rats repeatedly submitted to stressors in puberty, while a negative correlation was seen in controls (Cordero et al., 2013). Finally, the effects of vasopressin on aggression also depend on housing conditions and gender (Gutzler et al., 2010).

The findings briefly reviewed above show that the role of vasopressin in aggressive behavior may be dramatically changed by the condition of, and the type of aggression shown by subjects. Discrepancies of this kind are usually interpreted in terms of differences in experimental methodologies, which, however, are unlikely to have a major role here, because contrasting findings were obtained by overlapping sets of authors or within the same study. Discrepancies are more likely due to the complex impact of vasopressin on social behavior, which includes roles in social recognition, communication and motivation; in addition, its effects depend on social experience, hormonal background (e.g. testosterone), and other modulating neuronal inputs (e.g. serotonin) (Delville et al., 1996; Neumann et al., 2010; Stevenson and Caldwell, 2012; Takahashi et al., 2012). This suggests that the modulation of neuronal functions by vasopressin has integrating roles in aggression control, inherently involving strong dependence on conditions. This hypothesis was tested here by comparatively studying the effects of vasopressin deficiency in reproductively naive and reproductively experienced males, as well as in lactating females, with special reference to the forms and contexts of attacks displayed. Such subjects and their aggressiveness are naturally highly different; therefore, no comparisons between subject categories were performed. The role of vasopressin was inferred from the ability of vasopressin deficiency to affect aggressiveness in subjects having one particular background or gender. To investigate aspects of motivation, we also studied the role of vasopressin in impulsiveness, a behavioral feature strongly related to aggressiveness in both animals and humans (Scarpa and Raine, 1997; Cervantes and Delville, 2007). Noteworthy, recent findings from our laboratory demonstrated the role of vasopressin in controlling impulsivity in lactating but not in virgin females (M. Aliczki, A. Fodor, Z. Balogh, J. Haller, D. Zelena, unpublished observations).

The behavioral effects of vasopressin were studied here by using congenitally vasopressin-deficient $(-/-)$ Brattleboro rats, which are unable to secrete vasopressin due to a point mutation in the vasopressin gene. Non-deficient $\lambda^{+/+)}$Brattleboro rats were used as controls. Vasopressin 
deficient rats are the functional equivalents of $\mathrm{V} 1 \mathrm{a}-\mathrm{V} 1 \mathrm{~b}$ double knockout mice generated to study the behavioral consequences of totally compromised vasopressin neurotransmission (Yamaguchi et al., 2013), and are frequently employed to elucidate the role of vasopressin in various behaviors (Aarde and Jentsch, 2006; Fodor et al., 2012; Berquist li et al., 2013). Both V1a and V1b receptors are involved in the positive modulation of aggressive behavior (Albers, 2012; Stevenson and Caldwell, 2012) as such, no interference from receptor subtypes is to be expected from the elimination of vasopressin secretion in $-/-$ Brattleboro rats.

\section{Methods}

\subsection{Animals}

Vasopressin deficient and non-deficient Brattleboro rats came from a colony maintained in our Institute. The breeding stock was started from breeder rats provided by Harlan Laboratories (Indianapolis, USA); the vasopressin deficient and non-deficient lines were cross-bred for multiple generations to homogenize their genetic background. In all studies, litters were culled to 3 females and 3 males after parturition because litter size and offspring gender affect maternal behavior which can influence the behavior of offspring in adulthood (Moore and Morelli, 1979; Dimitsantos et al., 2007). The parents of $+/+$ male rats used in this study were homozygous for the non-mutated gene, while $-/$ - subjects originated from breeding pairs composed of $-\hat{l}-$ fathers and + I- mothers (Zelena et al., 2009). As such, the mothers of males (experiments 1 and 2 ) either belonged to the $+/-$ or to the $+/+$ genotype, the behavior of which is highly similar i.e. the behavior of offspring was not affected by differences in maternal care. In experiment 3 where females were studied, another confounding variable was also eliminated by pairing $+/+$ mothers with - / - females or $-/$ - mothers with + /+ males. Particularly, it was shown that the genotype of offspring may affect maternal behavior (Wolf and Wade, 2009); due to the genotype of parents, offspring always belonged to the ${ }_{\wedge}^{+} /$- genotype, which eliminated maternal bias engendered by the genotype of offspring. Maternal genotype was also balanced across experimental groups. Intruders (stimulus animals) used in aggression testing were male Wistar rats weighing approximately 250-300 g (Charles River, Hungary).

Rats were kept in a controlled environment $\left(23 \pm 1^{\circ} \mathrm{C}\right.$, 50-70\% humidity), in a 12:12 h day:night schedule for at least 10 days prior experimentation. Rats were housed in Makrolon cages $(40 \times 25 \times 25 \mathrm{~cm})$ containing sawdust bedding (Charles River, Hungary) and were given commercial rat chow (Charles River, Hungary) and tap water ad libitum. Because of excessive urination of $\bar{A}_{-} /-$animals, the bedding material was changed every second day for all animals during experimentation i.e. last time 2 days prior aggressive encounter. All studies were carried out in accordance with the European Communities Council Directive of 24 November 1986 (86/609/EEC) and were reviewed and approved by the Animal Welfare Committee of the Institute of Experimental Medicine, Budapest, Hungary.

\subsection{Behavioral tests}

\subsubsection{The resident-intruder test in males}

All tests assessing aggressive behavior were conducted in the early hours of the dark (active) phase as levels of aggression have been shown to be higher in this period (Haller et al., 2000). Subjects were faced with smaller Wistar opponents for $20 \mathrm{~min}$ in their home-cage. The encounter was performed under dim red illumination. Behavior was video recorded and scored later by an experimenter blind to treatment conditions. Behavioral analysis focused on the consummatory phase of aggressive behavior i.e. on biting attacks. In addition to quantitative measures (e.g. attack counts and latency), qualitative measures (attack type and context) were also recorded. The reason was that the impact of vasopressin on aggression seemed to depend on the form of attack performed by subjects in earlier studies (see Section 1). Attack episodes were analyzed in detail at low speed (frame-by-frame when necessary) for identifying the type of attacks. Hard and soft, vulnerable and non-vulnerable, as well as socially signaled and non-signaled attacks were differentiated. An attack was identified as hard bite when it involved kicking (clinch fights) or induced a strong startle response in the intruder (jumps or immediate submission). Soft bites were not associated with kicking and induced no response or mild quivering only. An attack was considered a vulnerable area-attack if it targeted the head (areas anterior to the ears), throat (the ventral area below the ears), belly (ventral areas between legs), or the paws of the opponent. The back and the flanks (posterior to the ears and dorsal to the legs) were considered non-vulnerable targets. An attack was considered signaled if it was delivered within an aggressive context (i.e. it was preceded by aggressive grooming, lateral threat, chasing, wrestling, offensive upright, and dominant posture), and it was considered nonsignaled if it was performed within a non-aggressive context (e.g. it was preceded by exploration, self-grooming or social investigation). Similar approaches were employed earlier (Halasz et al., 2009; Toth et al., 2012).

\subsubsection{The maternal aggression test}

Lactating female rats were faced with a male Wistar opponent in their home-cage on lactation days 5-6 and 18-19. The encounter lasted $10 \mathrm{~min}$ because of the severity of the maternal attacks. The behaviors recorded were similar to those investigated in the resident/intruder test. Behavior was video-recorded for $20 \mathrm{~min}$ after the termination of the encounter, during which the spontaneous maternal behavior of dams was recorded (time spent with nursing, and licking-grooming the pups).

\subsubsection{The delay discounting task}

The task was conducted in automated operant chambers equipped with two nose-poke holes with infrared sensors and LED lights, a chamber light and a feeder device with a magazine where food pellets were dropped (Med Associates, St. Albans, USA). Chambers were individually placed into sound attenuated wooden cubicles and were computercontrolled via the Med-PC IV software (Med Associates, St. Albans, VT, USA). 12 operant chambers were used i.e. 12 rats were tested in parallel; the apparatus was cleaned with 
ethanol and dried before each trial. The procedure was similar to that employed by Adriani et al. (2003). The feeding of subjects was restricted throughout the study to increase their motivation for food rewards. During the training phase animals were daily placed into the chambers for $30 \mathrm{~min}$ on 5 consecutive days. Nose-pokes (responses) into one of the holes was rewarded with one $45 \mathrm{mg}$ food pellet (small reward), while responses on the other hole resulted in five food pellets (large reward). Both types of reward were presented immediately after the response and were followed by a $25 \mathrm{~s}$ timeout period when responses were not rewarded but were registered. The side (left or right) of the nosepoke hole associated with the large reward was balanced over subjects. All rats developed a strong (90-95\%) preference for the side that was associated with the large reward. The test phase was performed 2 days after the last training session and lasted 8 days. The procedure was similar to that described for the training phase, but a delay was inserted between nose pokes and the delivery of the large rewards. Small rewards were delivered without a delay. The delay of large reward was progressively increased over subsequent days (delays were $10,20,30,45,60,80,100$, and $120 \mathrm{~s}$ on testing days $1,2,3,4,5,6,7$, and 8 , respectively). Nose pokes performed during delays and timeout periods were not rewarded but were recorded. Due to the delay in delivery, subjects gradually shifted their preference from the large reward to the immediate small reward. This shift (small reward preference) is considered an indicator of impulsive responses. An additional measure of impulsiveness was the number of inadequate responses i.e. the sum of responses shown during timeouts and delays.

\subsection{Experimental design}

The impact of vasopressin deficiency on aggressive behavior was tested in three experiments involving three different conditions: younger reproductively inexperienced, older reproductively experienced males and lactating females. In experiment 1 , initially group housed, 3 month-old $+/+$ and - / - males were transferred into individual cages (body weight: $381.1 \pm 11.2 \mathrm{~g}$ and $313.9 \pm 12.5 \mathrm{~g}$, sample size: 10 and 8 , respectively). This procedure assists the development of territorial behavior and aggressiveness. Subjects had no reproductive experience and were experimentally naive. The resident/intruder test was performed 3 days later as described above. The subjects of experiment 2 were reproductively experienced $+/+$ and $-/-$ male rats (body weight: $601.0 \pm 17.5 \mathrm{~g}$ and $461.3 \pm 15.5 \mathrm{~g}$, sample size: 6 and 9 , respectively). Rats were kept together with a female for about 5 months, during which the pair delivered several litters. Subjects were $7-8$ month-old by the time of aggression testing. They were transferred to test cages $(41.3 \times 26 \times 29.5 \mathrm{~cm}) 3$ days before experimentation; females and pups were removed from the cage $1 \mathrm{~h}$ before resident/intruder testing. Experiment 3 investigated the impact of vasopressin on maternal aggression. Subjects were 3 month-old primiparous $+/+$ and $-/-$ female rats (sample size was 13 and 10 , respectively). Animals were tested for maternal aggression on both the 5 th-6th and 18th-19th day of lactation, because the level of maternal aggression shows considerable changes over the lactation period, and the effects of vasopressin also change over time (Nephew and Bridges, 2008; Nephew et al., 2010). Body weights were $259.1 \pm 4.3 \mathrm{~g}(+/+)$ and $250.5 \pm 10.0 \mathrm{~g}(-/-)$ in the early, and $269.2 \pm 4.7 \mathrm{~g}(+/+)$ and $274.3 \pm 8.3 \mathrm{~g}(-/-)$ in the late phase of lactation. Subjects were moved to test cages $(41.3 \times 26 \times 29.5 \mathrm{~cm}) 3$ days before the first aggression testing, and were maintained there for the rest of the lactation period.

The impact of vasopressin deficiency on impulsiveness was investigated in a different set of rats submitted to the delay discounting task. Subjects were 3 month-old reproductively and experimentally naive male and 3 monthold experimentally naive primiparous lactating female rats (experiments 4 and 5, respectively). Sample size was 10 per group in both experiments. Subject selection for this type of testing was guided by the findings of the aggression tests.

\subsection{Statistical analysis}

Data were expressed as mean \pm SEM. Data obtained in the resident-intruder test were analyzed by single-factor ANOVA. Data obtained in the maternal aggression and delay discounting task were analyzed by repeated measures ANOVA; Factor 1 was time whereas Factor 2 was genotype. Pairwise comparisons were made by the Duncan test where the main effects were significant. The results of post hoc comparisons underwent Bonferroni correction (Holm's procedure) for multiple comparisons. The level of significance was set at $p<0.05$.

\section{Results}

\subsection{Aggressive behavior}

Reproductively inexperienced $+/+$ and $-/-$ males delivered a similar number of attacks after a similar latency (counts: $F_{\text {genotype }}(1,16)=0.06 ; p=0.81$; latency: $F_{\text {genotype }}(1,16)=0.09$; $p=0.76$; Fig. 1). Thus, vasopressin deficiency did not change the overall level of aggressiveness. However, a marked decrease in hard bites was noticed in vasopressin deficient rats. While attacks delivered by controls were hard bites in over $50 \%$ of cases, similar bites were delivered by about $10 \%$ of $-/-$ rats $\left(F_{\text {genotype }}(1,16)=5.17 ; p=0.037\right)$. The share of vulnerable and non-signaled attacks was low and was not affected by vasopressin deficiency (vulnerable area attacks: $F_{\text {genotype }}(1,16)=0.37 ; p=0.54$; non-signaled attacks $F_{\text {genotype }}(1,16)=0.06 ; p=0.81 ;$ Fig. 1$)$. Thus, vasopressin deficiency decreased the intensity of aggression by dramatically lowering the share of hard bites in reproductively inexperienced rats.

Reproductively experienced males showed considerably higher levels of aggression as shown by both attack counts and the share of hard bites (Fig. 1). No genotype differences were noticed at any of the variables recorded. Attack latencies were somewhat larger in vasopressindeficient males; however, the difference was not significant ( $\left.F_{\text {genotype }}(1,13)=3.25 ; p=0.094\right)$. In addition, the marginal delay in the initiation of attacks did not affect other measures of aggression ( $F$ values were between 1.35 and 0.01 ; corresponding $p$ values were between 0.26 and 0.92 for 
Reproductively inexperienced males
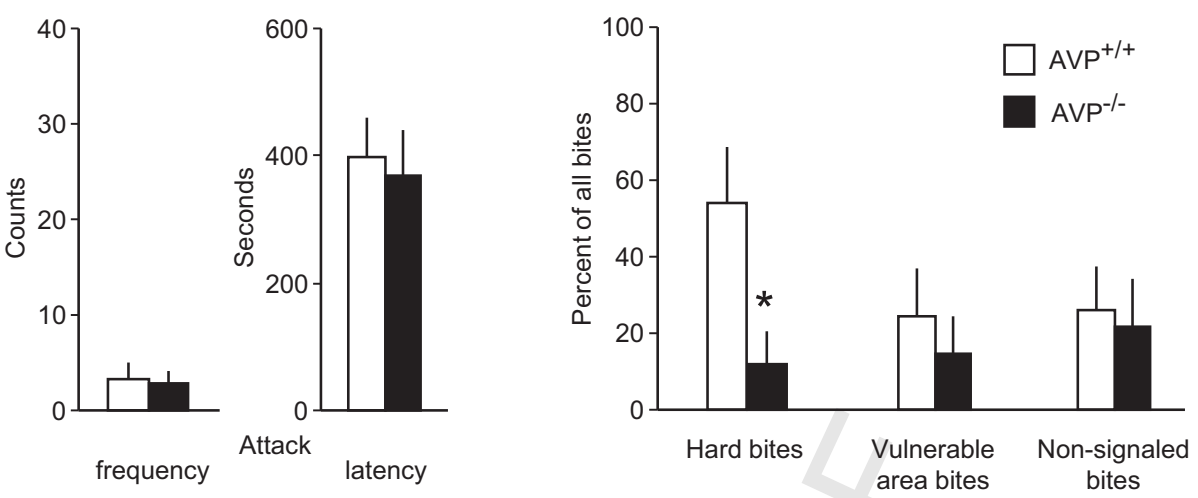

Reproductively experienced males
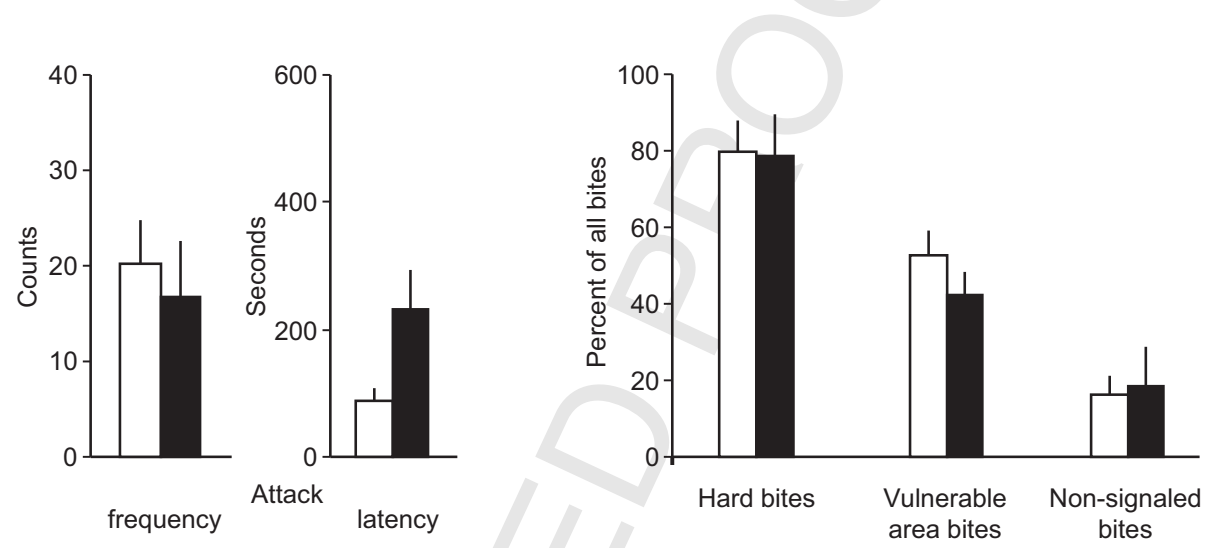

Figure 1 The effects of vasopressin deficiency on aggression in males. AVP, vasopressin; ${ }^{*} R<0.05$.

other variables). Thus, vasopressin deficiency had no impact on aggressiveness in reproductively experienced males.

Maternal aggression was extremely strong in the early phase of lactation and decreased but remained intense in the late lactation period (Fig. 2). Note that the duration of the test was $10 \mathrm{~min}$, while the resident/intruder test in males lasted $20 \mathrm{~min}$. Vasopressin deficiency had a strong effect on aggressiveness throughout. Attack counts decreased over time $\left(F_{\text {time }}(1,21)=40.11 ; p=0.0001\right)$ and were smaller in $-/-$ females $\left(F_{\text {genotype }}(1,21)=6.08\right.$; $p=0.022)$; the interaction between factors was not significant $\left(F_{\text {interaction }}(1,21)=3.33 ; p=0.08\right)$. The same was seen with attack latencies $\left(F_{\text {time }}(1,21)=18.62, p=0.0003\right.$; $F_{\text {genotype }}(1,21)=7.04, \quad p=0.014 ; \quad F_{\text {interaction }}(1,21)=3.84$; $p=0.06)$. There was an interaction between factors in the case of hard bites $\left(F_{\text {genotype }}{ }^{*}\right.$ time $\left.(1,21)=7.15 ; p=0.014\right)$ and vulnerable area bites $\left(F_{\text {genotype }}{ }^{*}\right.$ time $\left.(1,21)=6.85 ; p=0.016\right)$. In both cases, a decrease was noticed in vasopressindeficient rats in the late phase of lactation $(p<0.002$ for both variables). Non-signaled attacks were affected by lactation phase only $\left(F_{\text {time }}(1,21)=7.21 ; p=0.013\right.$; $F_{\text {genotype }}(1,21)=0.66, \quad p=0.42 ; \quad F_{\text {interaction }}(1,21)=2.83$; $p=0.11)$. Thus, maternal aggression was strongly affected by vasopressin deficiency; the effect was stronger in late phases of lactation when both quantitative and qualitative measures of attacks were altered.

\subsection{Spontaneous maternal behavior after the aggression test}

In the early phase of lactation, vasopressin deficient mothers spent significantly less time above the nest (nursing: ( $\left.F_{\text {genotype }}(1,20)=6.84 ; p=0.016\right)$ and the duration of lickinggrooming behavior was also reduced $\left(F_{\text {genotype }}(1,20)=4.77\right.$; $p=0.041)$. No similar differences were observed in late lactation (Table 1).

\subsection{The delay discounting task}

In males, increasing delays in large reward delivery increased the preference for the immediate small reward $\left(F_{\text {delay }}(7,126)=32.52 ; p<0.0001\right)$. The change was significant for delays larger than $30 \mathrm{~s}$. Vasopressin deficiency, however, had no impact and there was no interaction between the factors $\left(F_{\text {genotype }}(1,18)=0.01 ; p=0.98\right.$; $F_{\text {interaction }}(7,126)=0.64 ; p=0.72 ;$ Fig. 3$)$. The same pattern of main effects was observed for inadequate responses $\left(F_{\text {delay }}(7,126)=7.37 ; \quad p=0.0001 ; \quad F_{\text {genotype }}(1,18)=0.52\right.$; $\left.p=0.47 ; \quad F_{\text {interaction }}(7,126)=0.76 ; p=0.62\right)$. No significant changes were seen between the first and the rest of the testing phase days. 

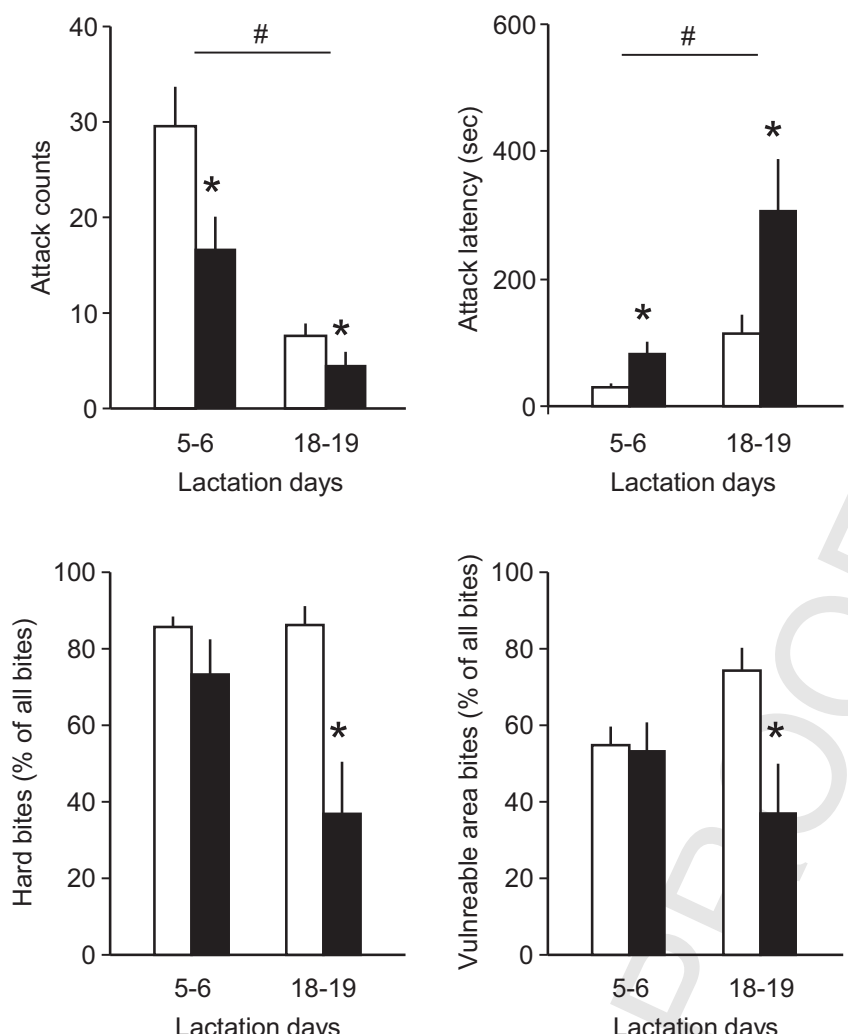

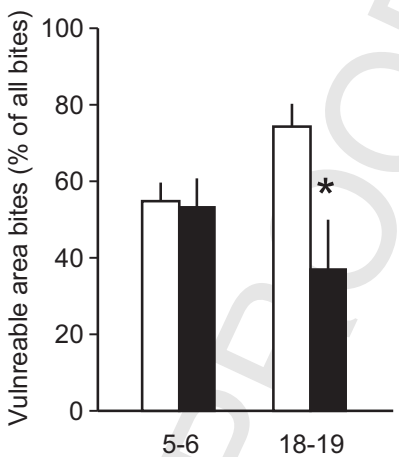

Lactation days

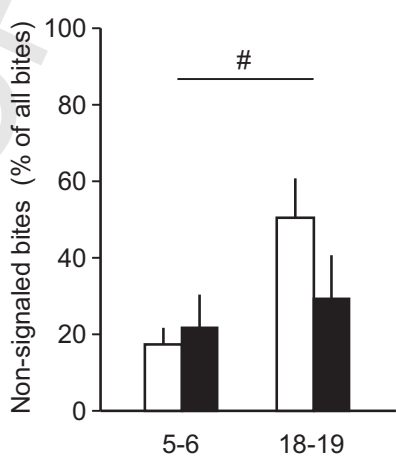

Lactation days

Figure 2 The impact of vasopressin deficiency on maternal aggression. AVP, vasopressin; \#, significant differences between early and late lactation period; *, significant genotype differences. In both cases, $p$ was smaller than 0.05.

The delay in large reward delivery increased the preference for the small reward in lactating females as well $\left(F_{\text {delay }}(7,126)=22.09 ; p=0.0001 ;\right.$ Fig. 3$)$. This time, however, the effect of genotype was also significant $\left(F_{\text {genotype }}(1,18)=5.13 ; p=0.036\right)$. No interaction between factors was observed $\left(F_{\text {interaction }}(7,126)=1.02 ; p=0.42\right)$; therefore, group differences were also shown as average preferences for the small reward (see upper right-hand panel of Fig. 3). It is noteworthy, however, that small reward preference increased significantly in controls at delays longer than 30 , while the same shift in preferences occurred in $-/$ - rats at delays longer than 80 s (Fig. 3, upper righthand panel). The interaction between factors was significant in the case of inadequate responses $\left(F_{\text {interaction }}(7,126)=6.20\right.$; $p=0.0001$ ). Such responses increased toward the end of the testing phase in controls. No increase was seen in $\bar{\Lambda}_{-} /$rats; the two genotypes showed significant differences at delays longer than $60 \mathrm{~s}$,

Taken together, these findings show that impulsivityrelated measures of the delay discounting task were not affected by vasopressin deficiency in reproductively inexperienced males, but impulsivity was strongly decreased in vasopressin-deficient lactating females.

\section{Discussion}

We tested here the dependence of the vasopressin/aggression relationship on the gender and reproductive state of subjects. In an attempt to corroborate this interaction with other behavioral features controlled by vasopressin, we also studied impulsiveness.

Table 1 Maternal behavior over the $20 \mathrm{~min}$ that followed the $10 \mathrm{~min}$-long aggressive interaction.

\begin{tabular}{llll}
\hline Lactation phase & Genotype & \multicolumn{2}{l}{ Duration of maternal behavior (s) } \\
\cline { 3 - 4 } & & Nursing & Licking-grooming \\
\hline 5th-6th day & $+/+$ & $686.4 \pm 108.9$ & $334.2 \pm 71.9$ \\
& $\Lambda^{/-}$ & $325.4 \pm 75.5^{*}$ & $136.1 \pm 31.17^{*}$ \\
18th-19th day & $+/+$ & $316.0 \pm 113.6$ & $95.1 \pm 33.0$ \\
& $\Lambda^{/-}$ & $360.8 \pm 136.5$ & $98.0 \pm 45.1$ \\
\hline
\end{tabular}

* Significant genotype differences $(R<0.05)$. 
Reproductively inexperienced males

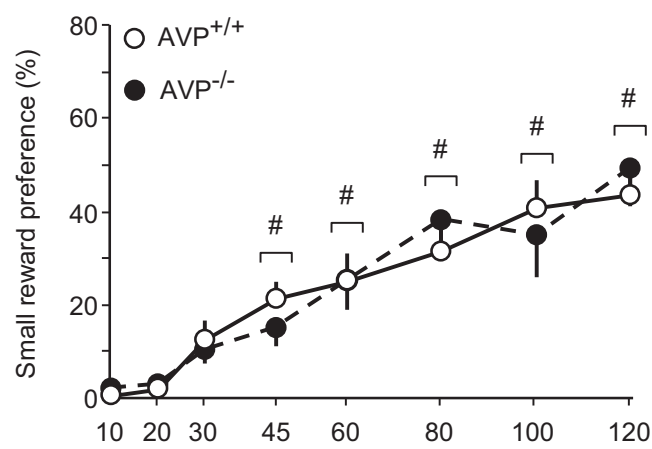

Lactating females

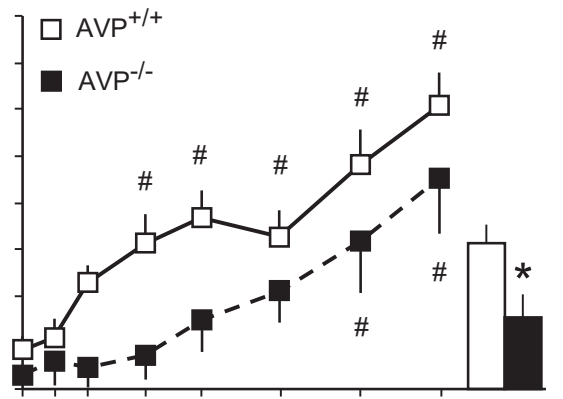

$\begin{array}{llllll}102030 & 45 & 60 & 80 & 100 & 120\end{array}$

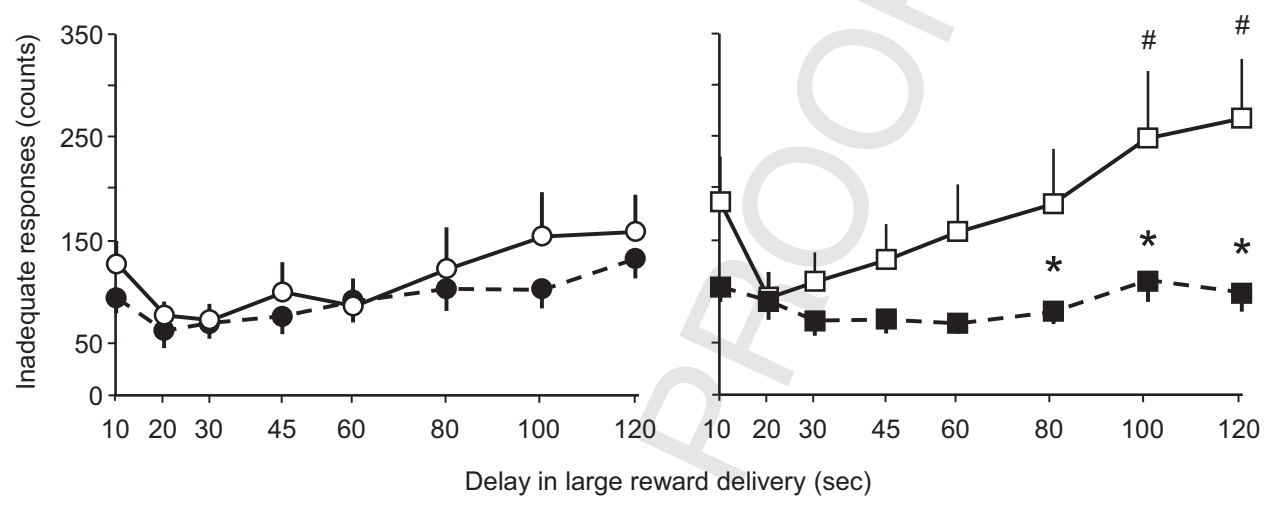

Figure 3 Vasopressin deficiency-induced changes in impulsivity as shown by the delay discounting task. AVP, vasopressin; \#, significant changes induced by large reward delay; *, significant genotype differences. In both cases, $p$ was smaller than 0.05 .

The disruption of vasopressin synthesis strongly decreased aggressiveness in lactating female rats, decreased the share of violent attacks in reproductively inexperienced male rats, and had no effect on aggressiveness in reproductively experienced males. Impulsivity as measured by the delay discounting task was markedly decreased by vasopressin deficiency in lactating females but not in males.

Earlier findings show that the impact of vasopressin on aggressive behavior is not only modulated by the condition of subjects, but this may even change the direction of the interaction. E.g. the positive modulation of aggressiveness by hypothalamic vasopressin seems inverted in subjects repeatedly defeated in adolescence (Ferris and Potegal, 1988; Delville et al., 1998), and the correlation between plasma vasopressin and aggressiveness was reversed also in female rats exposed to stressors in adolescence (Cordero et al., 2013). The aggression-promoting role of vasopressin in the lateral septum was lost in rats selected for anxiety (Beiderbeck et al., 2007; Veenema et al., 2010). In the present study, the vasopressin/aggression relationship was not reversed by the condition of subjects, but the findings confirm the modulating impact of the latter on the former. Basal levels of aggressiveness did not seem to have a role either. While the level of aggressiveness increased in the order "reproductively inexperienced males" < "maternal aggression in late lactation" < "reproductively experienced males" < "maternal aggression in early lactation", the impact of vasopressin deficiency increased in the order "reproductively experienced males" (no effect) < "reproductively inexperienced males" (qualitative changes in aggression) < "maternal aggression in early lactation" (quantitative changes) < "maternal aggression in late lactation"' (both quantitative and qualitative changes). Thus, the impact of vasopressin on aggressiveness appears to be modulated by factors other than basal aggressiveness. We acknowledge, however, that age may have been a confounding factor in the case of males, as age has an impact on aggressiveness (Honess and Marin, 2006); therefore, one cannot rule out that the interaction between vasopressin and aggressiveness was age-dependent.

Gender and reproductive state seem to be among the main factors that affected the impact of vasopressin on aggression. No effects were observed in reproductively experienced males, while the number of violent attacks (hard bites) was dramatically reduced by vasopressin deficiency in reproductively inexperienced males. This raises the possibility that testosterone production (largely different in these two types of animals) had an impact on the effects of vasopressin deficiency in males. Vasopressin status per se does not affect testosterone production (Szot and Dorsa, 1993); as such, the effects observed in our study are unlikely to be mediated by this endocrine route. Nevertheless, vasopressin and testosterone affect aggressiveness interactively (Delville et al., 1996; Neumann et al., 2010; Albers, 2012; Stevenson and Caldwell, 2012; Takahashi et al., 2012). One can hypothesize that the lack of effect in reproductively experienced males was due to the high testosterone plasma levels typical to their condition, which 
made them less sensitive to the modulating effects of vasopressin; in sexually inexperienced males where the plasma levels of testosterone are lower, the relative importance of vasopressin likely increases. Alternatively, brain areaspecific effects of vasopressin (which are opposite in certain cases as amply discussed in Section 1) may cancel out each other, and this phenomenon may be stronger in sexually experienced males.

Considerably stronger effects were obtained in lactating females, where the vasopressin system is activated by parturition and lactation, and plays important roles in maternal behaviors (Landgraf et al., 1991; Walker et al., 2001; Bosch and Neumann, 2012). Our findings confirm these findings; nevertheless, maternal behaviors were decreased by vasopressin deficiency in the early phase of lactation only, while maternal aggressiveness was reduced in both phases, suggesting that various aspects of maternal behaviors are independently controlled by vasopressin. Our further data suggest that the effects of vasopressin deficiency on maternal aggression were mediated by the strong impact of vasopressin deficiency on impulsiveness. Noteworthy, impulsivity is one of the factors that affect aggressiveness in both animals and humans, and their co-occurrence was observed in several transgenic lines (Garza-Trevino, 1994; Brunner and Hen, 1997; Scarpa and Raine, 1997; Chiavegatto and Nelson, 2003; Cervantes and Delville, 2007). No similar interactions were seen in reproductively inexperienced males, where vasopressin still influenced aggression. One reason might be that the level of aggressiveness per se (as shown by biting attack counts and attack latency) was not altered in these subjects, while the forms of attack may not depend on impulsiveness. Alternatively, the triple interaction between vasopressin neurotransmission, impulsiveness and aggression is specific to lactating females. Besides impulsivity, one cannot rule out that the interaction between vasopressin deficiency and aggression in lactating females was mediated factors other than impulsivity, as delays of increasing length in the delay discounting task can promote frustration (Evenden and Ryan, 1996). The clarification of the particular roles played by impulsivity and frustration sensitivity needs further studies.

An interesting finding of our studies was the dissociation of effects on aggression levels and attack patterns. In reproductively inexperienced males, the total number of attacks was not, while the share of hard bites was decreased by vasopressin deficiency. In lactating females, the levels of aggression were decreased at both time-points, while hard bites and attacks on vulnerable targets were decreased in late lactation only. Thus, general effects on aggression and specific effects on violent attacks dissociated in both males and females. This finding may be relevant for rodent models of abnormal aggression, where the forms of attack are in focus (see (Haller and Kruk, 2006) and (Haller, 2013) for reviews). All the subjects of the present studies showed natural forms of aggressiveness; yet the above-mentioned role-reversals of vasopressin were observed in models of abnormal aggression, and a role for vasopressin in human aggression was also revealed in personality disordered subjects (Coccaro et al., 1998; Delville et al., 1998; Beiderbeck et al., 2007; Cordero et al., 2013).

The mechanism by which the developmental absence of vasopressin affects aggressiveness was not investigated here. However, it was shown that vasopressin deficiency affects the brain levels of monoamines in Brattleboro rats (Dawson et al., 1990). Changes induced in serotonergic neurotransmission appear especially relevant in this respect, as serotonin per se and its interactions with vasopressin neurotransmission play important roles in aggression control (Ferris, 2000; Veenema et al., 2006; Morrison and Melloni, 2014). Therefore, one cannot rule out that the behavioral changes noticed here are not exclusively due to the lack of vasopressin but to developmental interactions with other neurotransmitter systems e.g. serotonin.

Taken together, our findings confirm the role of vasopressin in aggression, show that this role depends on the gender and reproductive state of subjects and possibly on their age, suggest that the effects of vasopressin on maternal aggression develop in conjunction with impulsivity and/or altered sensitivity to frustration, and hint to the possibility that vasopressin plays a specific role in violent forms of aggression, which forecasts roles in the development of abnormal forms of aggressiveness.

\section{Role of the funding source}

This study was supported by the Hungarian National Science Q2 552 and Research Fund (OTKA) contract grant number: 82069 and by the Intramural Research Program of the National Institute on Drug Abuse, NIH, DHHS.

\section{Conflict of interest}

None declared.

\section{Acknowledgments}

This study was supported by the Hungarian National Science and Research Fund (OTKA) contract grant number: 82069 and Q3 56 by the Intramural Research Program of the National Institute on Drug Abuse, NIH, DHHS.

\section{References}

Aarde, S.M., Jentsch, J.D., 2006. Haploinsufficiency of the argininevasopressin gene is associated with poor spatial working memory performance in rats. Horm, Behav. 49, 501-508.

Adriani, W., Seta, D.D., Dessi-Fulgheri, F., Farabollini, F., Laviola, G., 2003. Altered profiles of spontaneous novelty seeking, impulsive behavior, and response to $D$-amphetamine in rats perinatally exposed to bisphenol A. Environ Health Perspect. 111, 395-401.

Albers, H.E., 2012. The regulation of social recognition, social communication and aggression: vasopressin in the social behavior neural network. Horm, Behav. 61, 283-292.

Beiderbeck, D.I., Neumann, I.D., Veenema, A.H., 2007. Differences in intermale aggression are accompanied by opposite vasopressin release patterns within the septum in rats bred for low and high anxiety. Eur J. Neurosci. 26, 3597-3605.

Beiderbeck, D.I., Reber, S.O., Havasi, A., Bredewold, R., Veenema, A.H., Neumann, I.D., 2012. High and abnormal forms of aggression in rats with extremes in trait anxiety - involvement of the dopamine system in the nucleus accumbens. Psychoneuroendocrinology 37, 1969-1980.

Berquist Ii, M.D., Mooney-Leber, S.M., Feifel, D., Prus, A.J., 2013. Assessment of attention in male and female Brattleboro rats 
using a self-paced five-choice serial reaction time task. Brain Res 1537, 174-179.

Bosch, O.J., 2013. Maternal aggression in rodents: brain oxytocin and vasopressin mediate pup defence. Philos, Trans. R. Soc. Lond. B: Biol. Sci. 368, 20130085.

Bosch, O.J., Neumann, I.D., 2012. Both oxytocin and vasopressin are mediators of maternal care and aggression in rodents: from central release to sites of action. Horm, Behav. 61, 293-303.

Brunner, D., Hen, R., 1997. Insights into the neurobiology of impulsive behavior from serotonin receptor knockout mice. Ann, N. Y. Acad. Sci. 836, 81-105.

Caldwell, H.K., Young 3rd, W.S., 2009. Persistence of reduced aggression in vasopressin $1 \mathrm{~b}$ receptor knockout mice on a more "wild" background. Physiol, Behav. 97, 131-134.

Carrillo, M., Ricci, L.A., Melloni, R.H., 2011. Glutamate-vasopressin interactions and the neurobiology of anabolic steroid-induced offensive aggression. Neuroscience 185, 85-96.

Caughey, S.D., Klampfl, S.M., Bishop, V.R., Pfoertsch, J., Neumann, I.D., Bosch, O.J., Meddle, S.L., 2011. Changes in the intensity of maternal aggression and central oxytocin and vasopressin V1a receptors across the peripartum period in the rat. J, Neuroendocrinol. 23, 1113-1124.

Cervantes, M.C., Delville, Y., 2007. Individual differences in offensive aggression in golden hamsters: a model of reactive and impulsive aggression? Neuroscience 150, 511-521.

Cheng, S.Y., Delville, Y., 2009. Vasopressin facilitates play fighting in juvenile golden hamsters. Physiol, Behav. 98, 242-246.

Chiavegatto, S., Nelson, R.J., 2003. Interaction of nitric oxide and serotonin in aggressive behavior. Horm. Behav. 44, 233-241.

Coccaro, E.F., Kavoussi, R.J., Hauger, R.L., Cooper, T.B., Ferris, C.F., 1998. Cerebrospinal fluid vasopressin levels: correlates with aggression and serotonin function in personality-disordered subjects. Arch, Gen. Psychiatry 55, 708-714.

Compaan, J.C., Buijs, R.M., Pool, C.W., De Ruiter, A.J., Koolhaas, J.M., 1993. Differential lateral septal vasopressin innervation in aggressive and nonaggressive male mice. Brain Res, Bull. 30, $1-6$.

Cordero, M.I., Ansermet, F., Sandi, C., 2013. Long-term programming of enhanced aggression by peripuberty stress in female rats. Psychoneuroendocrinology 38, 2758-2769.

Dawson Jr., R., Wallace, D.R., King, M.J., 1990. Monoamine and amino acid content in brain regions of Brattleboro rats. Neurochem, Res. 15, 755-761.

Delville, Y., Mansour, K.M., Ferris, C.F., 1996. Testosterone facilitates aggression by modulating vasopressin receptors in the hypothalamus. Physiol, Behav. 60, 25-29.

Delville, Y., Melloni Jr., R.H., Ferris, C.F., 1998. Behavioral and neurobiological consequences of social subjugation during puberty in golden hamsters. J Neurosci. 18, 2667-2672.

Dimitsantos, E., Escorihuela, R.M., Fuentes, S., Armario, A., Nadal, R., 2007. Litter size affects emotionality in adult male rats. Physiol, Behav. 92, 708-716.

Evenden, J.L., Ryan, C.N., 1996. The pharmacology of impulsive behaviour in rats: the effects of drugs on response choice with varying delays of reinforcement. Psychopharmacology (Berl) $128,161-170$.

Ferris, C.F., 2000. Adolescent stress and neural plasticity in hamsters: a vasopressin-serotonin model of inappropriate aggressive behaviour. Exp. Physiol., 85 Spec No. 85S-90S.

Ferris, C.F., Melloni Jr., R.H., Koppel, G., Perry, K.W., Fuller, R.W., Delville, Y., 1997. Vasopressin/serotonin interactions in the anterior hypothalamus control aggressive behavior in golden hamsters. J Neurosci. 17, 4331-4340.

Ferris, C.F., Potegal, M., 1988. Vasopressin receptor blockade in the anterior hypothalamus suppresses aggression in hamsters. Physiol, Behav. 44, 235-239.
Fodor, A., Klausz, B., Pinter, O., Daviu, N., Rabasa, C., Rotllant, D., Balazsfi, D., Kovacs, K.B., Nadal, R., Zelena, D., 2012. Maternal neglect with reduced depressive-like behavior and blunted c-fos activation in Brattleboro mothers, the role of central vasopressin. Horm, Behav. 62, 539-551.

Garza-Trevino, E.S., 1994. Neurobiological factors in aggressive behavior. Hosp, Community Psychiatry 45, 690-699.

Gobrogge, K.L., Liu, Y., Young, L.J., Wang, Z., 2009. Anterior hypothalamic vasopressin regulates pair-bonding and druginduced aggression in a monogamous rodent. Proc, Natl. Acad. Sci. USA. 106, 19144-19149.

Griebel, G., Simiand, J., Serradeil-Le Gal, C., Wagnon, J., Pascal, M., Scatton, B., Maffrand, J.P., Soubrie, P., 2002. Anxiolytic- and antidepressant-like effects of the non-peptide vasopressin V1b receptor antagonist, SSR 149415, suggest an innovative approach for the treatment of stress-related disorders. Proc. Natl. Acad. Sci. USA. 99, 6370-6375.

Gutzler, S.J., Karom, M., Erwin, W.D., Albers, H.E., 2010. Arginine-vasopressin and the regulation of aggression in female Syrian hamsters (Mesocricetus auratus). Eur. J. Neurosci. 31, 1655-1663.

Halasz, J., Zelena, D., Toth, M., Tulogdi, A., Mikics, E., Haller, J., 2009. Substance $P$ neurotransmission and violent aggression: the role of tachykinin NK(1) receptors in the hypothalamic attack area. Eur J. Pharmacol. 611, 35-43.

Haller, J., 2013. The neurobiology of abnormal manifestations of aggression - a review of hypothalamic mechanisms in cats, rodents, and humans. Brain Res, Bull. 93, 97-109.

Haller, J., Kruk, M.R., 2006. Normal and abnormal aggression: human disorders and novel laboratory models. Neurosci, Biobehav. Rev. 30, 292-303.

Haller, J., Millar, S., van de Schraaf, J., de Kloet, R.E., Kruk, M.R. 2000. The active phase-related increase in corticosterone and aggression are linked. J, Neuroendocrinol. 12, 431-436.

Honess, P.E., Marin, C.M., 2006. Behavioural and physiological aspects of stress and aggression in nonhuman primates. Neurosci. Biobehav. Rev. 30, 390-412.

Kelly, A.M., Goodson, J.L., 2013. Functional significance of a phylogenetically widespread sexual dimorphism in vasotocin/vasopressin production. Horm, Behav. 64, 840-846.

Landgraf, R., Neumann, I., Pittman, Q.J., 1991. Septal and hippocampal release of vasopressin and oxytocin during late pregnancy and parturition in the rat. Neuroendocrinology 54 378-383.

Moore, C.L., Morelli, G.A., 1979. Mother rats interact differently with male and female offspring. J, Comp. Physiol. Psychol. 93, 677-684.

Morrison, T.R., Melloni Jr., R.H., 2014. The role of serotonin, vasopressin, and serotonin/vasopressin interactions in aggressive behavior. Curr. Top Behav. Neurosci..

Nephew, B.C., Bridges, R.S., 2008. Central actions of arginine vasopressin and a V1a receptor antagonist on maternal aggression, maternal behavior, and grooming in lactating rats. Pharmacol Biochem. Behav. 91, 77-83.

Nephew, B.C., Byrnes, E.M., Bridges, R.S., 2010. Vasopressin mediates enhanced offspring protection in multiparous rats. Neuropharmacology 58, 102-106.

Neumann, I.D., Veenema, A.H., Beiderbeck, D.I., 2010. Aggression and anxiety: social context and neurobiological links. Front Behav. Neurosci. 4, 12.

Scarpa, A., Raine, A., 1997. Psychophysiology of anger and violent behavior. Psychiatr, Clin. N. Am. 20, 375-394.

Stevenson, E.L., Caldwell, H.K., 2012. The vasopressin 1b receptor and the neural regulation of social behavior. Horm, Behav. 61 $277-282$.

Szot, P., Dorsa, D.M., 1993. Expression of vasopressin mRNA in extrahypothalamic nuclei of the homozygous Brattleboro rat 
is not modulated by testosterone. Neuroendocrinology 58 , 381-387.

Takahashi, A., Quadros, I., Almeida, R.M., Miczek, K., 2012. Behavioral and pharmacogenetics of aggressive behavior. In: Cryan, J.F., Reif, A. (Eds.), Behavioral Neurogenetics. Springer Berlin Heidelberg, pp. 73-138.

Toth, M., Tulogdi, A., Biro, L., Soros, P., Mikics, E., Haller, J., 2012. The neural background of hyper-emotional aggression induced by post-weaning social isolation. Behav ${ }_{\wedge}$ Brain Res. 233, 120-129.

Veenema, A.H., Beiderbeck, D.I., Lukas, M., Neumann, I.D., 2010. Distinct correlations of vasopressin release within the lateral septum and the bed nucleus of the stria terminalis with the display of intermale aggression. Horm, Behav. 58, 273-281.

Veenema, A.H., Blume, A., Niederle, D., Buwalda, B., Neumann, I.D., 2006. Effects of early life stress on adult male aggression and hypothalamic vasopressin and serotonin. Eur, J. Neurosci. 24, 1711-1720.

Walker, C.D., Toufexis, D.J., Burlet, A., 2001. Hypothalamic and limbic expression of CRF and vasopressin during lactation: implications for the control of ACTH secretion and stress hyporesponsiveness. Prog, Brain Res. 133, 99-110.

Wolf, J.B., Wade, M.J., 2009. What are maternal effects (and what are they not)? Philos, Trans. R. Soc. Lond. B: Biol. Sci. 364, 1107-1115.

Yamaguchi, Y., Suzuki, T., Mizoro, Y., Kori, H., Okada, K., Chen, Y., Fustin, J.M., Yamazaki, F., Mizuguchi, N., Zhang, J., Dong, X., Tsujimoto, G., Okuno, Y., Doi, M., Okamura, H., 2013. Mice genetically deficient in vasopressin $\mathrm{V} 1 \mathrm{a}$ and $\mathrm{V} 1 \mathrm{~b}$ receptors are resistant to jet lag. Science 342, 85-90.

Zai, C.C., Muir, K.E., Nowrouzi, B., Shaikh, S.A., Choi, E., Berall, L., Trepanier, M.O., Beitchman, J.H., Kennedy, J.L., 2012. Possible genetic association between vasopressin receptor $1 \mathrm{~B}$ and child aggression. Psychiatry Res, 200, 784-788.

Zelena, D., Langnaese, K., Domokos, A., Pinter, O., Landgraf, R., Makara, G.B., Engelmann, M., 2009. Vasopressin administration into the paraventricular nucleus normalizes plasma oxytocin and corticosterone levels in Brattleboro rats. Endocrinology 150, 2791-2798. 